\title{
Modeling and simulation of friction stir welding process for AA6061-T6 aluminum alloy using finite element method
}

\author{
Muleta Tiki Lemi $^{a^{*}}$, Endalkachew Mosisa Gutema ${ }^{a}$ and Mahesh Gopal ${ }^{a}$
}

${ }^{a}$ Department of Mechanical Engineering, College of Engineering and Technology, Wollega University, Post Box No: 395, Nekemte, Ethiopia

\begin{tabular}{l}
\hline A R T I C L E I N F O \\
\hline Article history: \\
Received 27 May 2021 \\
Accepted 2 February 2022 \\
Available online \\
3 February 2022 \\
\hline Keywords: \\
Frictions stir welding (FSW) \\
Modeling and Simulation \\
Finite Element Method (FEM) \\
Heat generation and Heat \\
transfer
\end{tabular}
\begin{abstract}
A B S T R A C T
Friction Stir Welding (FSW) is a process of welding materials that generates heat through friction. Plastic deformation, nonlinear material movement, tool-to-structural evolution friction, and heat production from friction and plastic deformation all have an impact on FSW operation. In this paper, thermo-mechanical characteristics of aluminum alloy AA6061-T6 during the FSW process were simulated based on COMSOL $®$ software using a finite element approach. A conceptual model was created to interpret the thermal and structural analyses. According to the obtained results, the temperature rises on the top and bottom surfaces as the axial force increases but decreases along the line perpendicular to the weld direction. The overall temperature decreases as the forward welding speed rises within the acceptable induced temperature range of the workpiece, while the axial force and rotational speeds stay stable.
\end{abstract}

\section{Introduction}

Friction stir welding (FSW) is one of the new advancements in modern welding technology. This thermo-mechanical process requires additional heat to cause metal deformation that alters regional behavior without affecting the remaining material. A perishable rotary tool with a specifically constructed pin and shoulder was put into the adjacent edges of the sheets. The tool serves two purposes: (a) heating the work piece and (b) moving the material to form a joint. Friction was caused between the tool and the work piece, so the material is heated as plastic deformation occurs (Mishra \& Ma, 2005). Backar et al., (2020) demonstrated that the material flow during FSW is highly intricate, depending on the device structure, process parameters, and welding substance. Understanding and recognizing the product flow behavior is critical to improving tool design and ensuring high-performance structural welds. During FSW, the activities are divided into various phases. The workpiece and tool move relative to each other, and it was described at a period. During the first, the tool rotates at a period and is plunged vertically through the joint line between work components. In the second phase, the engagement creates heat through frictional effort and material deformation due to the tool's velocity differential and the work piece (Schmidt et al., 2004). Chao et al., (2003) conducted the experiment using the FSW method and derived the expression for heat transfer using the boundary value problem method considering stationary conditions for the tool and transient requirements for the work piece to determine the heat flux generated by friction in the tool and workpiece using numerical finite element method (FEM). The findings show that about $95 \%$ of heat is caused due to friction transported to the work piece and only $5 \%$ transported to the tool. Zhu \& Chao, (2004) developed an FEA code to analyze three-dimensional heat transfer and thermo-mechanical computer simulation modeling using WELDSIM of 304L stainless steel to evaluate the variation on transient temperature and residual stress in the FSW process and also compared the results between neutron diffraction technique and numerical simulation. Such results * Corresponding author.

E-mail addresses: tikimuleta@gmail.com (M. T. Lemi) 
show that the numerical simulation has excellent agreement with the experiments. Hamilton et al., (2008) optimized the energy per unit length of welded material using a slip factor experiment to measure welding temperatures of aluminum alloys using thermal modeling, resulting in energy levels between 800 and $2000 \mathrm{~J} / \mathrm{mm}$, with excellent agreement between experimental data and the thermal model. The welded joints' microhardness, tensile, and bending tests were measured using FEM in a dissimilar FSW experiment employing aluminum alloys 6061-T6 and 6082-T6. The AA6082-T6 material has lower yield and ultimate stress, according to (Moreira et al., 2009). Using the FSW technique, Atharifar et al., (2009) performed a CFD model to evaluate the heat transfer and material flow of Aluminum alloy 6061 to analyze the viscous and inertia loads. The findings show that longitudinal force has the greatest influence on transverse velocity. FSW experiment was performed by Prasanna et al., (2010) using Aluminium -AA6061-T6 to estimate the maximum temperature by altering the input parameters using ANSYS. Thermal conductivity, specific heat, and density are measured using the trend line equations. The results show that when varying rotational speeds at a constant welding speed, temperature decreases with the direction perpendicular to the tool on the top surface, higher hardness values were obtained, and maximum tensile strength was obtained using the tensile test in the maximum temperature region. They also utilized ANSYS software using a finite element modeling experiment to determine the maximum temperature in stainless steel using the FSW method. The results demonstrated that the peak temperature of $1056.853^{\circ} \mathrm{C}$ was obtained using simulation comparatively lower than the melting point of $304 \mathrm{~L}$ steel, and the mean relative error between theoretical and experimental data for $304 \mathrm{~L}$ steel was also calculated. Nguyen et al., (2011) used the FSSW modeling approach to examine the hardness values and strengths of the FSSW joints using the prediction model of failure experiment utilizing aluminum alloy 6061-T6 sheets. According to that work, this FSSW approach is best suited for determining the failure load of materials and structural frames. To evaluate the microstructural development and thermomechanical behavior, the ABAQUS software is used to weld two dissimilar metals, AA6061-T6 and AA5086-O, using the FSW approach. Jamshidi Aval et al., (2011) concluded that hardness in the AA5086 side is primarily determined by recrystallization, whereas hardness in the AA6061 side is determined by the size, volume fraction, and distribution of causes in the weld line and together heat affected zone. Ganesh \& Kumar, (2011) used Finite Element Simulation and die forming to conduct an FSW experiment to weld super plastic AA 6061-T6 sheets. As a result, during the forming process, the superior interlocked of the material increases in the area of the bulging shape. Kiral et al., (2013) used the finite element method (FEM) to calculate the temperature distribution of aluminum alloys using FSW. They found that at the tool holding period and rotating speed rises, the temperature is maximum near the welding joint, and when the tool transverse speed rises, the temperature was decreased. The FEM investigation was done to investigate the process of FSW to analyze the welding competence of AZ31 magnesium alloy. The DEFORM 3D finite element model is used to model the experiment. Gök \& Aydin, (2013) observed that material moved per rotation raised and temperature decreased proportionally the transverse speed was raised. To assess microstructure, impacts of materials location, welding speed, micro hardness, and tensile property of the welded joints, the FSW experiment was done using two different materials: AA6061 and AA7075 alloy. According to the experimental results, the most strength is obtained at the welded material's joints when welding was done at the fastest speed (Guo et al., 2014). Using FEM, Vignesh et al., (2016) explored the distribution analysis to forecast the greatest temperature during the FSW process of Aluminum AA6061-T6 alloy material by considering tool rotating speed, welding speed, and diameter of both shoulder and pin. They concluded that the greatest temperature is obtained and is related to shoulder speed and diameter, whereas welding speed is inversely proportional. The CFD model was developed by taking into account AA6061-T6 material to measure forces in a tool utilizing the FSW technique. The FEM model was built to compute welding tool fatigue stress by Zhang et al., (2016), and they concluded that fatigue stresses rise with increased rotation speed and decrease with increased transverse speed. Meyghani et al., (2017) experimented with comparing the thermal behavior of FSW welding using Lagrangian, FEM, Arbitrary Lagrangian-Eulerian, and Eulerian techniques. Finally, they stated that the Lagrangian technique is an acceptable tool for modeling structural dissimilar components. Zhu et al., (2017) developed a 3D coupled thermomechanical FEM model to predict and examine defect creation during FSW using the coupled Eulerian-Lagrangian approach, taking the parameters as welding temperature, zone shape, and void size. According to their findings, welding at a low speed or with a fast rotational speed of the tool generates a smaller void. During the FSW operation, the friction force is the primary source of heat production. Axial power, rotational speeds, and transverse speeds are used as input parameters to model thermal activity using the ABAQUS program. Meyghani \& Awang, (2020) concluded that if the rotational speed increases, the highest temperature in the work piece also increases. The temperature distribution and residual thermal stresses produced by the FSW process are predicted using the FEM system. The temperature of AA5083-O joints is measured using an infrared thermal image sensor, and the findings show that welding speed is increased results the high temperature is attained in welding phase, although rotating speed is increased resulted in a highest temperature is attained (El-Sayed et al., 2018). The aim of the research published by Iqbal et al., (2019) is to study the force variance, flow behavior and temperature distribution at work piece of the AA6005 aluminum alloy. Point tracking method is used to predict the welding defect, and the outcome to get a good weld with a plunge depth of $0.3 \mathrm{~mm}$ between the pipe and tool shoulder. Meyghani et al., (2019) studied the material temperature and elastic modulus values of the FSW process and modelled the process using MATLAB ${ }^{\circledR}$ and ABAQUS $^{\circledR}$ software to solve the governing equations of FSW joints made of 6061-T6 aluminum alloy. They compared the results by using error percentage and the results also showed that the temperature is always lower than the melting point of 6061-T6 aluminum alloy, which is $580^{\circ} \mathrm{C}$, during all stages of welding.

In previous works, the researchers have used various materials to predict temperature distribution, welding defect, thermo-mechanical properties, fatigue and fracture tests, hardness, and tensile property of weldments and the role of input parameters such as tool rotating speed, welding speed, the diameter of both shoulder and pin, of the material using different experimental studies (Akbari et al. 2019; Taheri-Behrooz et al. 2019; Narasimharaju \& Sankunny 2019; 
Aliha et al. 2019,2020; Torabi et al. 2018,2019; Shubhavardhan \& Surendran 2018; Mohammadaliha et al. 2018 ; Jian et al. 2018; Marazani et al. 2021) and different software such as MATLAB ${ }^{\circledR}$, ABAQUS $^{\circledR}$, ANSYS, and WELDSIM ${ }^{\circledR}$. However, a limited amount of research is accessible to develop a simulation model using COMSOLMultiphysics ${ }^{\circledR}$ software to assess the steady-state convection-conduction heat transfer model and explore Aluminum's thermal and structural analysis of Aluminum (AA6061- T6) alloy. Hence in this research, thermomechanical characteristics of AA6061-T6 during the FSW process were simulated based on COMSOL ${ }^{\circledR}$ software using finite element modeling and analysis. Also, a conceptual model was created to interpret thermal and structural studies.

\section{Material Properties for simulation}

Aluminum alloy (AA6061- T6) was used as the material for the analysis. The main advantages for preferring AA6061-T6 over other aluminum alloys are its appropriateness for solid-state welding, high power, strong workability, good corrosion resistance, and extensive application in automotive and aerospace sectors Riahi \& Nazari, (2011). CPM-IV steel tool H13 steel was utilized for modeling because of its hardness and heat transfer qualities. The chemical and temperature-dependent mechanical characteristics of aluminum alloy AA6061-T6 are shown in Tables 1 and 2 .

Table 1. Chemical composition of AA6066-T6 aluminum

\begin{tabular}{cccccccccc}
\hline $\mathbf{M g}$ & $\mathbf{S i}$ & $\mathbf{F e}$ & $\mathbf{C u}$ & $\mathbf{Z n}$ & $\mathbf{T i}$ & $\mathbf{M n}$ & $\mathbf{C r}$ & Others & Al \\
\hline $0.8 \%-$ & $0.4 \%-$ & $0.7 \%$ & $0.15 \%-$ & $0.25 \%$ & $0.15 \%$ & $0.15 \%$ & $0.04 \%-$ & $0.05 \%$ & balance \\
$1.2 \%$ & $0.8 \%$ & & $0.40 \%$ & & & & $0.35 \%$ & & \\
\hline
\end{tabular}

Table 2. Temperature dependence of shear yield strength of AA6066-T6 aluminum alloy

\begin{tabular}{lllllllllll} 
Temperature (K) & 311 & 339 & 366 & 394 & 422 & 450 & 477 & 533 & 589 & 644 \\
\hline Yield stress (MPa) & 241 & 238 & 232 & 223 & 189 & 138 & 92 & 34 & 19 & 12 \\
\hline
\end{tabular}

The $320 \mathrm{~mm} \times 102 \mathrm{~mm} \times 12.7 \mathrm{~mm}$ dimensions of the workpiece are considered for simulation work, as shown in Fig. 1. The unthreaded pin and shoulder are taken to model the analysis. The welding instrument's pin diameter is 12 $\mathrm{mm}$, its shoulder diameter is $50 \mathrm{~mm}$, its tool height is $90 \mathrm{~mm}$, and its pin height is $4.5 \mathrm{~mm}$. In the numerical model, half of the welded plate is treated as a weld line, while the other half is an asymmetric line. The symmetric condition was used to save simulation time.
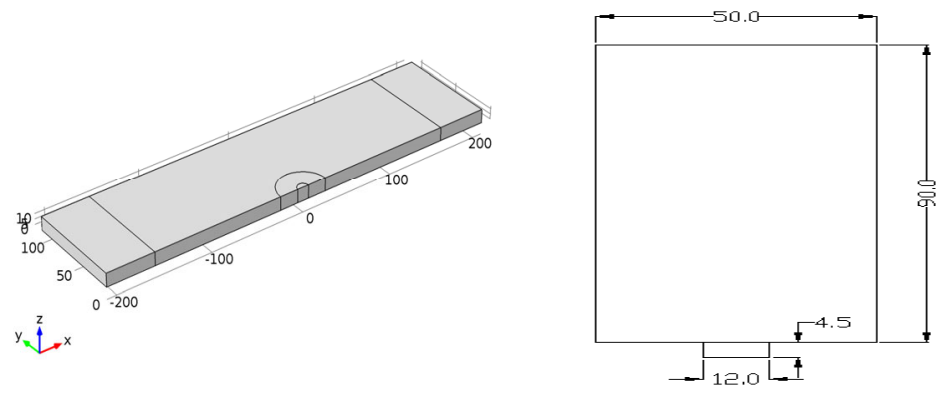

Fig. 1. Work piece geometry for FSW modeling (all dimensions in: $\mathrm{mm}$ ).

\section{Mathematical Model and Boundary Conditions}

\subsection{Mathematical Model}

Using the coordinate transformation method, COMSOL multiphysics software was utilized to create a steady-state convection-conduction heat transport model. Meanwhile, the mechanical model was intended to calculate residual stresses caused by the FSW operation's heat flux. It exemplifies the fundamental idea of modeling and simulation by representing the physical system of the process using a mathematical equation. 


\subsubsection{Governing Equations for Thermal Analysis}

Vignesh et al. (2016) presented the governing partial differential equation for thermal energy conservation and heat transfer processes that result in the work piece plate during the FSW process as:

$$
\rho \mathrm{C}_{\mathrm{p}} \frac{\partial \mathrm{T}}{\partial \mathrm{t}}=\nabla \cdot(\mathrm{k} \nabla \mathrm{T})-\rho \mathrm{C}_{\mathrm{p}} \mathrm{U} \cdot \nabla \mathrm{T}+\mathrm{Q}
$$

where,

T: Temperature field

U: Velocity vector of the tool

k: Heat conductivity

Cp: Heat capacity

$\rho: \quad$ Density of the work piece material

The expression $\rho \mathrm{C}_{\mathrm{p}} \mathrm{U} \cdot \nabla \mathrm{T}$ represents the convective term that occurs opposite to the conductive term due to the coordinate scheme of the welding tool. The equation has achieved its stationary condition when the time derivative variable entirely disappears. If the current model's tool velocity in the x-direction is positive, Eq. (1) changes to:

$$
\rho \mathrm{C}_{\mathrm{p}} \frac{\partial \mathrm{T}}{\partial \mathrm{t}}=\frac{\partial}{\partial \mathrm{x}}\left(\mathrm{k}_{\mathrm{x}} \frac{\partial \mathrm{T}}{\partial \mathrm{x}}\right)+\frac{\partial}{\partial \mathrm{y}}\left(\mathrm{k}_{\mathrm{y}} \frac{\partial \mathrm{T}}{\partial \mathrm{y}}\right)+\frac{\partial}{\partial \mathrm{z}}\left(\mathrm{k}_{\mathrm{z}} \frac{\partial \mathrm{T}}{\partial \mathrm{z}}\right)+\mathrm{u}_{\mathrm{x}} \rho \mathrm{C}_{\mathrm{p}} \frac{\partial \mathrm{T}}{\partial \mathrm{x}}+\mathrm{Q}
$$

The current established model computes the induced heat as surface heat flux due to the interaction between the tool pin and the work piece (surface heat friction and volumetric heat of deformation) proposed by Colegrove, (2000).

$$
\begin{array}{ll}
\mathrm{q}_{\mathrm{pin}}(\mathrm{T})=\frac{\mu}{\sqrt{3\left(1+\mu^{2}\right)}} \mathrm{r}_{\mathrm{p}} \omega \tau_{\mathrm{y}}(\mathrm{T}) \\
\mathrm{q}: & \text { pin heat flux }\left(\mathrm{W} / \mathrm{m}^{2}\right) \\
\mu: & \text { Friction coefficient between the pin and the work piece, } \\
\mathrm{rp}: & \text { Pin radius in mm } \\
\omega: & \text { Pin's angular velocity }(\mathrm{rad} / \mathrm{s}) \\
\tau_{\mathrm{y}}(\mathrm{T}): & \text { Average shear yield stress of the material as a function of } \\
& \text { temperature }
\end{array}
$$

The average shear stress is a function of temperature, and this model uses an interpolation function based on experimental results in Table 2 to estimate it. Furthermore, the heat is produced at the tool's shoulder and the work piece's interface. The local heat flux per unit area $\left(\mathrm{W} / \mathrm{m}^{2}\right)$ at a distance $\mathrm{r}$ from the tool center axis was determined by the following equation (Colegrove, 2000):

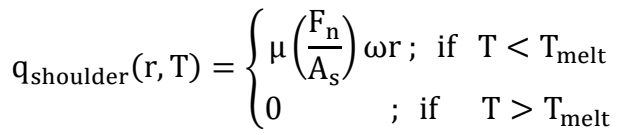

where,

Fn: $\quad$ Normal force

$\mathrm{A}_{\mathrm{s}}$ : $\quad$ Shoulder's surface area

$\mathrm{T}_{\text {melt: }}$ Aluminum melting temperature

The friction between the tool and the aluminum alloy layer is significantly less above the alloy's melting temperature. If the temperature is equal to or higher than the melting temperature, the model sets the heat production from the shoulder and the pin to zero.

\subsubsection{Governing Equation for Structural Analysis}

The governing partial differential equations for the structural analysis of the model are given by (Hetnarski \& Eslami, 2009) as:

$\nabla \sigma=0$ 


$$
\sigma=\mathrm{D}\left(\epsilon-\epsilon_{\mathrm{p}}-\epsilon_{\mathrm{th}}\right)
$$

where,

$\sigma$ : Cauchy stress tensor, expressing the conservation of momentum which is related to the well-known equilibrium equation 5 ,

$\epsilon: \quad$ Total strain tensor,

$\epsilon_{\mathrm{p}}: \quad$ Plastic strain tensor,

$\epsilon_{\mathrm{th}}$ : Thermal stress tensor,

D: $\quad$ Fourth order Hooke's tensor.

Additionally, the following kinematic equations describe the rate of change of $\epsilon_{\mathrm{p}}$ and the vector $\mathrm{K}$ of the model parameters.

$$
\begin{aligned}
& \dot{\epsilon_{\mathrm{p}}}=\lambda \mathrm{H}\left(\epsilon_{\mathrm{p}}, \mathrm{K}, \mathrm{p}\right) \\
& \dot{\mathrm{k}_{\mathrm{p}}}=\lambda \mathrm{G}\left(\epsilon_{\mathrm{p}}, \mathrm{K}, \mathrm{p}\right)
\end{aligned}
$$

where,

p: Vector containing variables from the solution vector (i.e., displacements and/or temperatures),

$\lambda$ : Plastic multiplier, which was determined by the complementary conditions

$$
\begin{aligned}
& F\left(\left(\epsilon_{p}, K, p\right) \leq 0\right. \\
& \lambda=0, \\
& F\left(\epsilon_{p}, K, p\right) \lambda=0
\end{aligned}
$$

in which $\mathrm{F}$ is Yield function. For isotropic hardening one can substitute

$$
\begin{aligned}
& K=\varepsilon_{\text {pe }} \\
& x=Y=f_{2}\left(\epsilon_{p}\right), \\
& F(\sigma, Y)=\varnothing(\sigma)-Y \\
& G=-\frac{\partial F}{\partial \sigma}=1
\end{aligned}
$$

The mathematical formulation of the model was confirmed by conveying the thermal strains in the model terms of components as:

$$
\begin{array}{ll}
\varepsilon_{\mathrm{ij}}^{\text {th }}=\alpha\left(\mathrm{T}-\mathrm{T}_{0}\right) \delta_{\mathrm{ij}} \\
\text { where, } & \\
\varepsilon_{\mathrm{ij}}^{\text {th }}: & \text { Components of the thermal strain tensor, } \\
\alpha: & \text { Thermal expansion coefficient of the material, } \\
\delta_{\mathrm{ij}}: & \text { Kronecker delta. }
\end{array}
$$

\subsection{Boundary Conditions}

\subsubsection{Boundary Conditions and Initial Conditions}

The model geometry is symmetric around the weld. Consequently, an aluminum plate with $320 \mathrm{~mm} \times 102 \mathrm{~mm} \times$ $12.7 \mathrm{~mm}$ was designed. Furthermore, the model is encircled in the $\mathrm{x}$-direction by two infinite domains, ensuring that measurements at the plate borders provide no results. The model does not incorporate the fluid flow parameters of the moving process in Aluminum. As a result, the model lacks the spinning tool's dynamic step changes and front-toback material transmission. The simulation domain, the thermal (red), and structural (green) boundary conditions are depicted in Fig. 2. 


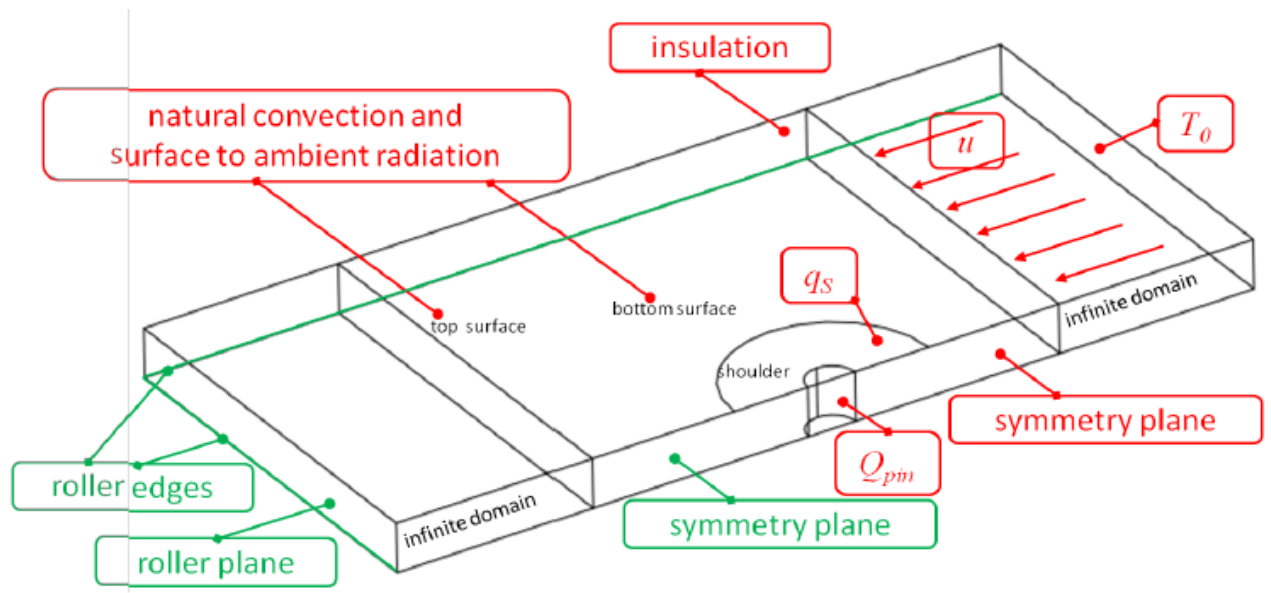

Fig. 2. Simulation domain and corresponding thermal (red) and structural (green) boundary conditions

\subsubsection{Thermal Boundary Conditions}

The heat produced by friction and plastic deformation during the FSW phase spreads rapidly across the aluminum plates. Due to convection and surface to atmospheric radiation, the top and bottom surfaces of the plates lose heat. Bejan \& Kraus, (2003) demonstrated the heat flux expressions at these surfaces.

$$
\begin{aligned}
& \mathrm{q}_{\text {top }}=\mathrm{h}_{\mathrm{up}}\left(\mathrm{T}_{0}-\mathrm{T}\right)+\varepsilon \sigma\left(\mathrm{T}_{\mathrm{amb}}^{4}-\mathrm{T}^{4}\right) \\
& \mathrm{q}_{\text {bottom }}=\mathrm{h}_{\text {bottom }}\left(\mathrm{T}_{0}-\mathrm{T}\right)+\varepsilon \sigma\left(\mathrm{T}_{\mathrm{amb}}^{4}-\mathrm{T}^{4}\right)
\end{aligned}
$$

where,

$\mathrm{h}_{\text {top }}$ and $\mathrm{h}_{\text {bottom: }} \quad \quad$ Heat transfer coefficients for natural convection,

$\mathrm{T}_{0}$ :

$\varepsilon:$

$\sigma:$

$\mathrm{T}_{\mathrm{amb}}$ : Accompanying reference temperature, Surface emissivity, Stefan-Boltzmann constant, Ambient air temperature.

Normal convection and surface-to-ambient radiation are utilized to simulate an infinite domain in an aluminum work piece where the temperature is in equilibrium with infinity. As a result, the border state was set to insulation at this point. Empirical equations may be used to calculate the particular values of the heat transfer coefficients given the associated boundary conditions. In this model, the values for $\mathrm{h}_{\text {top }}=12.25 \mathrm{~W} /\left(\mathrm{m}^{2} \mathrm{~K}\right)$ and $\mathrm{h}_{\text {bottom }}=6.25 \mathrm{~W} /\left(\mathrm{m}^{2} \mathrm{~K}\right)$ presented in Table 3 are employed.

\subsubsection{Structural Boundary Conditions}

The coupled thermo-mechanical impacts of the FSW process were simulated using a finite element modeling technique. The model in this study was based on existing material attributes that are inbuilt in the FEM software database, as directed by Obiko \& Mwema (2020) and Kumar \& Aggarwal (2015). The temperature distribution in the weldment was computed using steady-state heat flow analysis, and the structural model uses the results of the thermal analysis as feedback to calculate the mechanical Elasto-plastic characteristics of the weldment, such as stress and deformation. As a result, the following mechanical boundary conditions are specified. Clamping holds the work piece in place. The clamped regions of the plates are restricted in the $\mathrm{x}, \mathrm{y}$, and $\mathrm{z}$ axes. To protect at the bottom surfaces of the plates, the work piece's bottom nodes were constrained in the vertical direction (z-direction). Fig. 2 shows mechanical boundary conditions.

\subsubsection{Initial Condition}

The initial condition for the simulation is:

$\mathrm{T}(\mathrm{x}, \mathrm{y}, \mathrm{z}, 0)=\mathrm{Ti}$ 


\section{Meshed Model}

Three-dimensional free quadrilateral and free triangular elements were employed to mesh the plate and tool. The work piece and tool are separated into small finite elements along their length and breadth (10000 nodes \& 20000 elements). Fig. 3 depicts extremely fine meshes near the tool, with fines decreasing as distance from the tool increases. Convergence was generally achieved in 400 cycles with a tolerance level of $1^{\mathrm{e}-6}$.

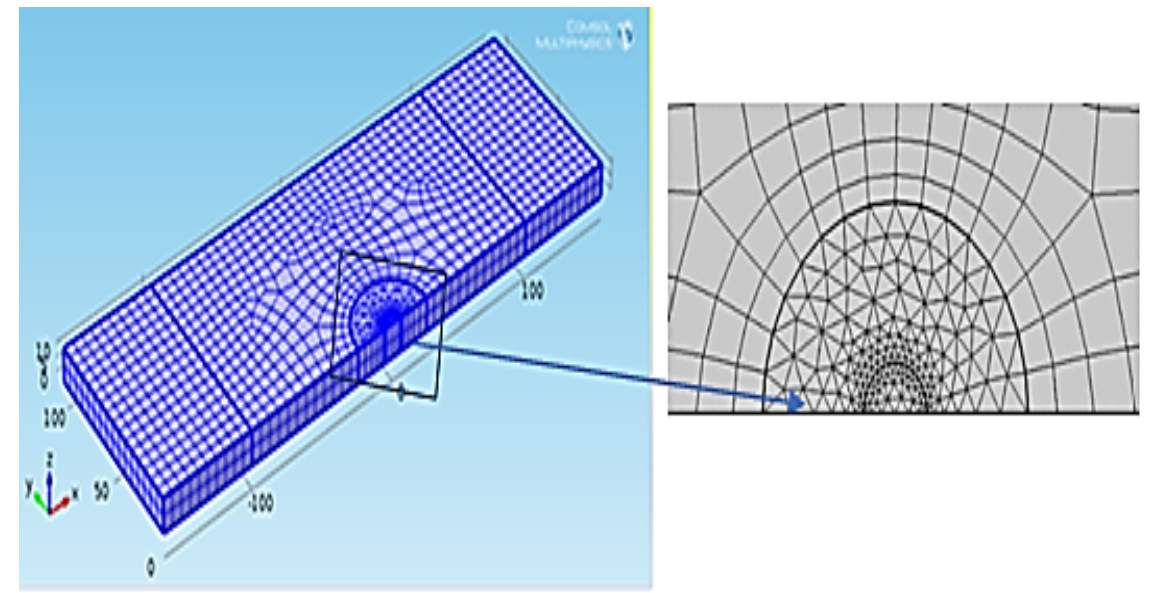

Fig. 3. Meshed model of work piece and tool used for the present study

\section{Sample Simulation Result}

The parameters mentioned in Table 3 were chosen for a sample numerical result. The COMSOL-Multiphysics software was utilized to simulate and model the heat transport and structural dynamics. In Equations 1 and 2 , the velocity vector was set to $u=\left(-u_{\text {weld }}, 0,0\right)$, where $u_{\text {weld }}$ specifies the tool's $\mathrm{x}$-direction translational velocity. The primary parameters that may be controlled during the FSW process are as follows.

Table 3. Welding input parameters used in the present model

\begin{tabular}{|c|c|c|}
\hline Name & Description & Values \\
\hline To & Ambient temperature & $300 \mathrm{~K}$ \\
\hline $\mathrm{T}_{\text {melt }}$ & Melting temperature of work piece & $933 \mathrm{~K}$ \\
\hline $\mathrm{h}_{\mathrm{u}}$ & $\begin{array}{l}\text { Heat transfer coefficient on the upside of the work } \\
\text { piece }\end{array}$ & $12.25 \mathrm{~W} /\left(\mathrm{m}^{2} . \mathrm{K}\right)$ \\
\hline $\mathrm{h}_{\mathrm{d}}$ & $\begin{array}{l}\text { Heat transfer coefficient on the downside of the work } \\
\text { piece }\end{array}$ & $6.25 \mathrm{~W} /\left(\mathrm{m}^{2} . \mathrm{K}\right)$ \\
\hline$\varepsilon$ & Surface emissivity & 0.3 \\
\hline $\mathrm{U}$ & Welding speed or tool traverse speed & $7.5 \mathrm{~mm} / \mathrm{s}$ \\
\hline$\mu$ & Coefficient of friction & 0.4 \\
\hline $\mathrm{n}$ & Tool rotational speed & $800 \mathrm{rpm}$ \\
\hline$\omega$ & Angular velocity & 2.pi (rad).n (rad) \\
\hline $\mathrm{F}_{\mathrm{n}}$ & Plunge force & $25 \mathrm{kN}$ \\
\hline$r_{\text {pin }}$ & Radius pin & $6 \mathrm{~mm}$ \\
\hline$r_{\text {shoulder }}$ & Radius of shoulder & $25 \mathrm{~mm}$ \\
\hline $\mathrm{c}_{\text {pin }}$ & Pin heat capacity & $500 \mathrm{~J} / \mathrm{kg} \mathrm{K}$ \\
\hline $\mathrm{q}_{\text {pin }}$ & Pin heat source & $\mathrm{w}$ \\
\hline $\mathrm{q}_{\text {shouldr }}$ & Shoulder heat source & w \\
\hline $\mathrm{q}_{\mathrm{u}}$ & Heat flux on the upper side of the work piece & $\mathrm{w} / \mathrm{m}^{2}$ \\
\hline $\mathrm{q}_{\mathrm{d}}$ & Heat flux on lower side of work piece & $\mathrm{w} / \mathrm{m}^{2}$ \\
\hline$A_{s}$ & Surface area of shoulder & $\mathrm{pi}^{*}(\mathrm{r}$ _shoulder $2-\mathrm{r}$ _ pin 2$)$ \\
\hline $\mathrm{P}_{\text {pin }}$ & Pin density & $7800 \mathrm{~kg} / \mathrm{m}^{3}$ \\
\hline
\end{tabular}


Fig. 4 shows the practical results of steady-state temperature distribution in the shape of both exterior surface distributions and equithermal surfaces for the case of $u_{\text {weld }}=7.5 \mathrm{~mm} / \mathrm{sec}$ and tool rotation of $800 \mathrm{rpm}$. Fig. 4 shows that, as expected, the temperature distribution is most significant where the spinning tool contacts with welding plates. The fresh cold plate connects ahead of the tool, while the welding mechanism transfers the hot welding behind it. $T_{\max }=906 \mathrm{~K}$ is the maximum temperature, which is lower than the melting point of the aluminum alloy in Table 3 . This Table displays the maximum induced temperature values and their location. The highest temperature, according to Jamshidi Aval et al., (2011), is created during the FSW phase ranges from $70 \%$ to $90 \%$ of the melting temperature of the workpiece composition, decreasing or eliminating welding faults and substantial distortion or deformation that are frequently linked with fusion welding. The estimated results are shown in Fig. 5, and it is quite close to the experimentally measured values.

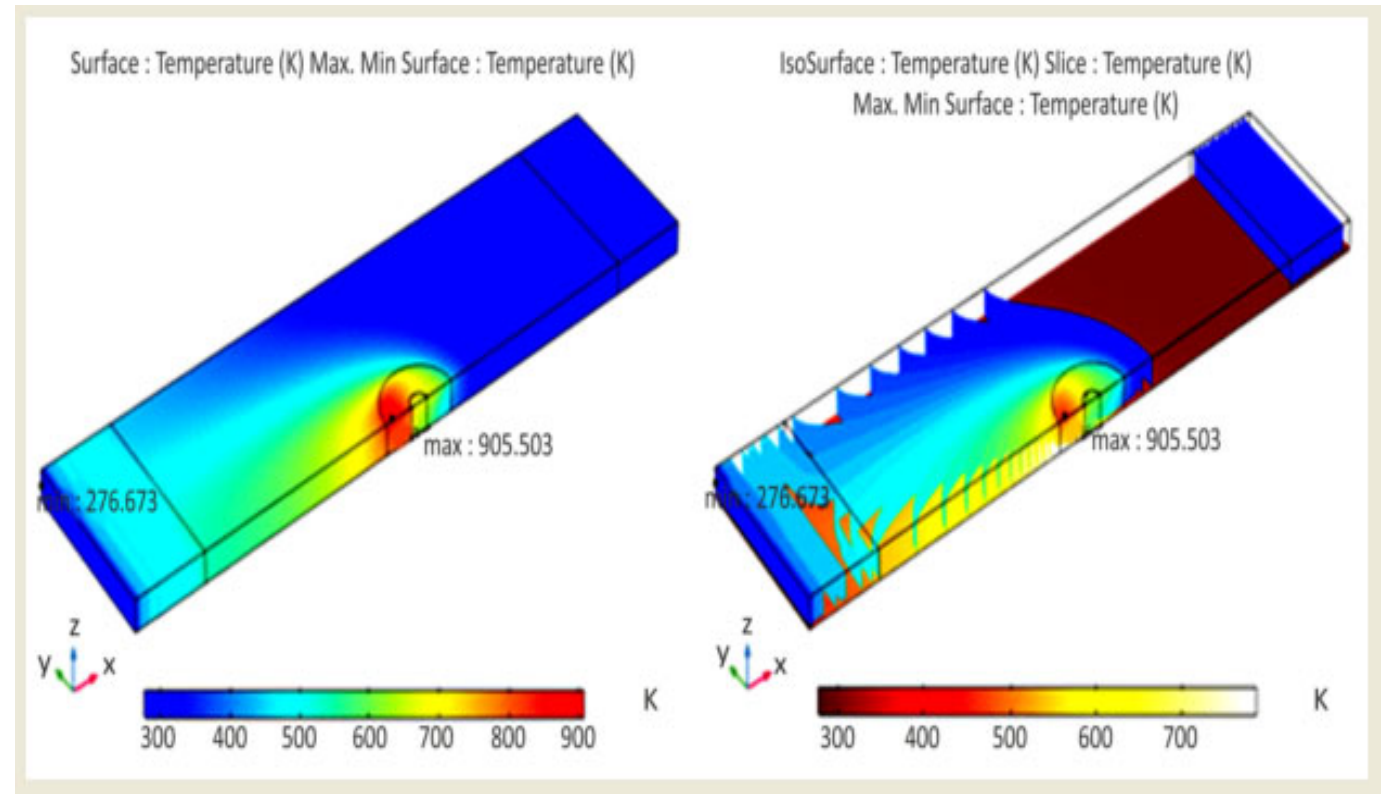

Fig. 4. Steady state temperatures distributions (a) on the surface (b) on equithermal surfaces via the volume

\section{Simulation results and Discussions}

The friction stir welding technique for AA6061-T6 material is described in detail, emphasizing modeling and simulation. In this evaluation of various welding settings, the thermal and structural analysis findings are reviewed. The results presented here were gathered systematically and thoroughly to gain a better knowledge of the weldments' thermal and mechanical efficiency.

\subsection{Thermal Analysis}

During FSW operation, frictional heat and heat-related plastic deformation tend to raise the temperature of the work piece. The developed model may predict better temperature distribution under various welding situations. The combined impacts of tool movement and rotation, boundary conditions, and welded AA 6061-T6 thermal characteristics were determined. Fig. 4 shows a three-dimensional model sample result for the welding settings listed in Table 3. Using as a starting point, a thorough analysis was conducted to identify the impacts of axial force rotational and translational tool rate on the thermal behavior of the weldments.

\subsection{Effect of Axial Force}

The axial load power is a significant measure for assessing a work piece's thermal activity. According to Equation 4 , the heat produced during the FSW process is proportional to the normal force. To investigate the impact of this force on heat distribution, the model was created and is subjected to various vertical forces while keeping the tool rotation and translation rates constant, as shown in Table 3. Fig. 5 shows temperature distribution contour plots on the workpiece surface for axial stresses of $7.5 \mathrm{kN}, 9 \mathrm{kN}, 10.5 \mathrm{kN}$, and $13 \mathrm{kN}$. The temperature gradient rises in the welding direction in front of the tool compared to its backside.

Additionally, as the axial load increases from $7.5 \mathrm{kN}$ to $13 \mathrm{kN}$, the heat produced during the process is improved. The determined axial load temperatures are also within the FSW process's acceptable temperature range for AA 6061T6. Maximum temperatures are higher near the weld line and lower when closer to the heat-affected region. In 
general, increasing the penetration force raises the maximum temperature; but, for higher axial forces, the maximum temperatures tend to converge to constant values, as shown in Fig. 6. Fig. 5 indicates that increasing the penetration force increases the maximum temperature increase. To investigate the behavior of the induced temperature over the top and bottom surfaces, as well as the thickness of the work piece, systematic and structured simulations were carried out. The temperature data on the top and bottom surfaces of the joints in a parallel perpendicular to the weld line are shown in Fig. 6. As shown in Fig. 7, the temperature decreases with distance along the top and bottom surfaces of the work piece. However, the maximum temperature at the bottom surface is lower than the equivalent value at the top surface.

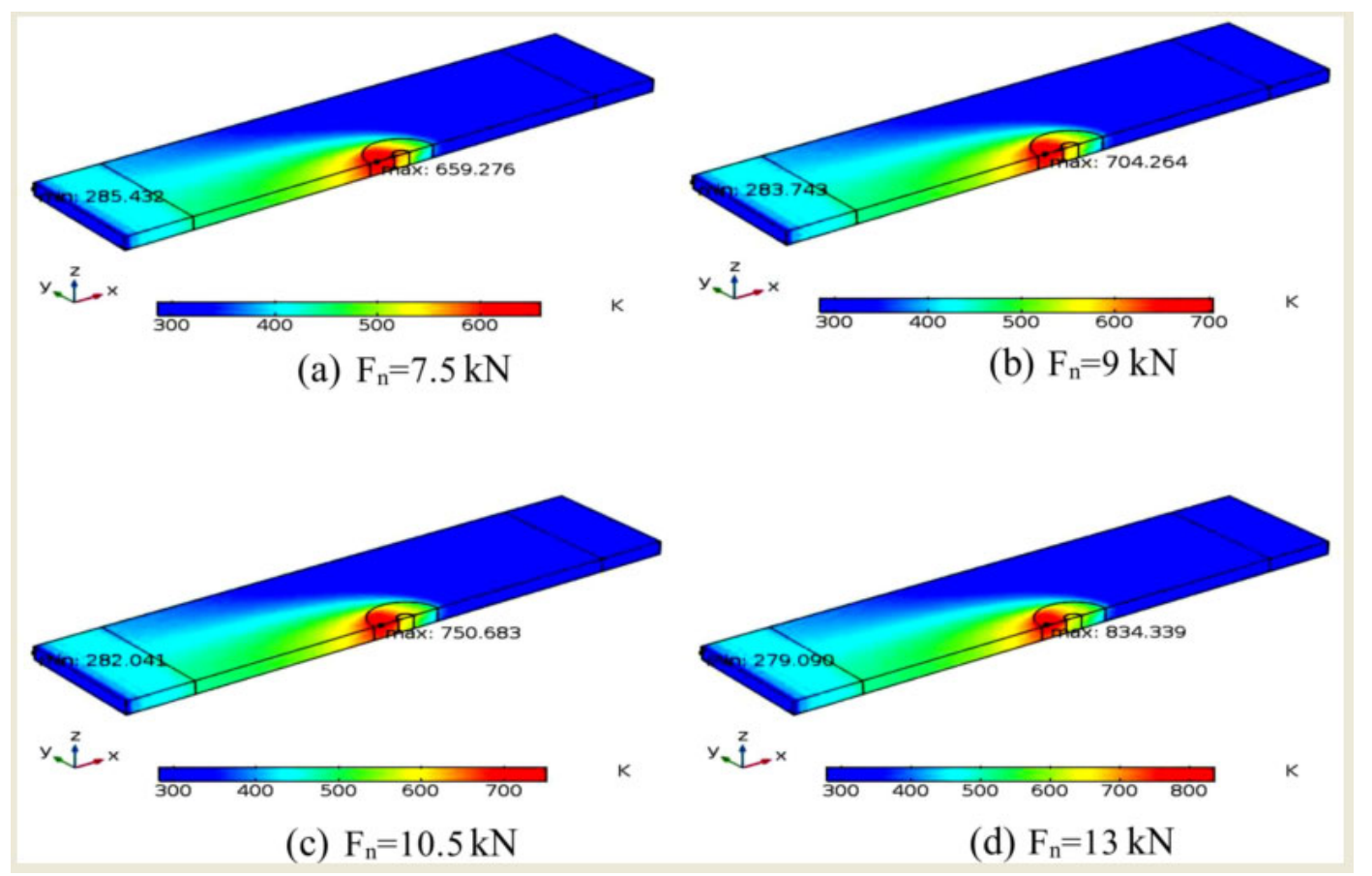

Fig. 5. Temperature distribution contours for different axial forces, rotational speed $800 \mathrm{rpm}$ and translational speed $7.5 \mathrm{~mm} / \mathrm{s}$

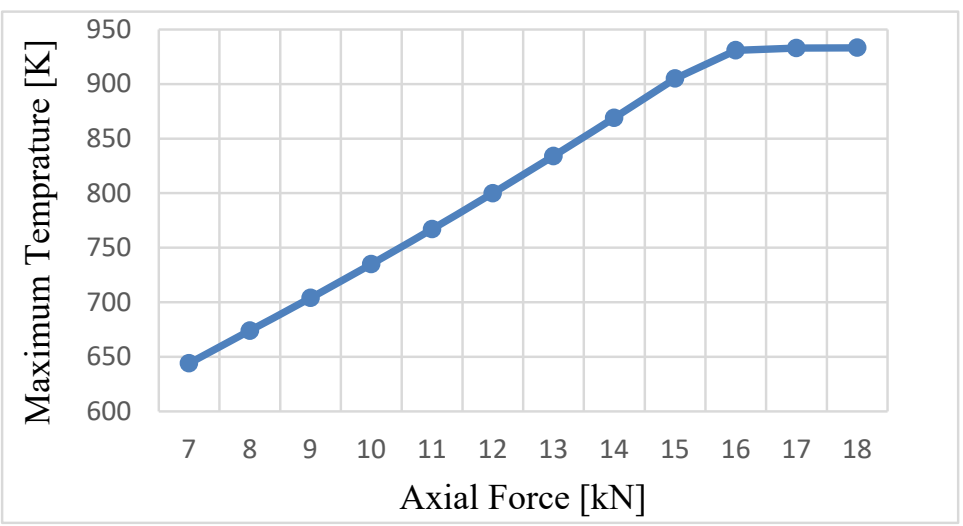

Fig. 6. Variation of Maximum Temperature as a function of axial force, rotational speed $800 \mathrm{rpm}$ and translational speed $7.5 \mathrm{~mm} / \mathrm{s}$ 

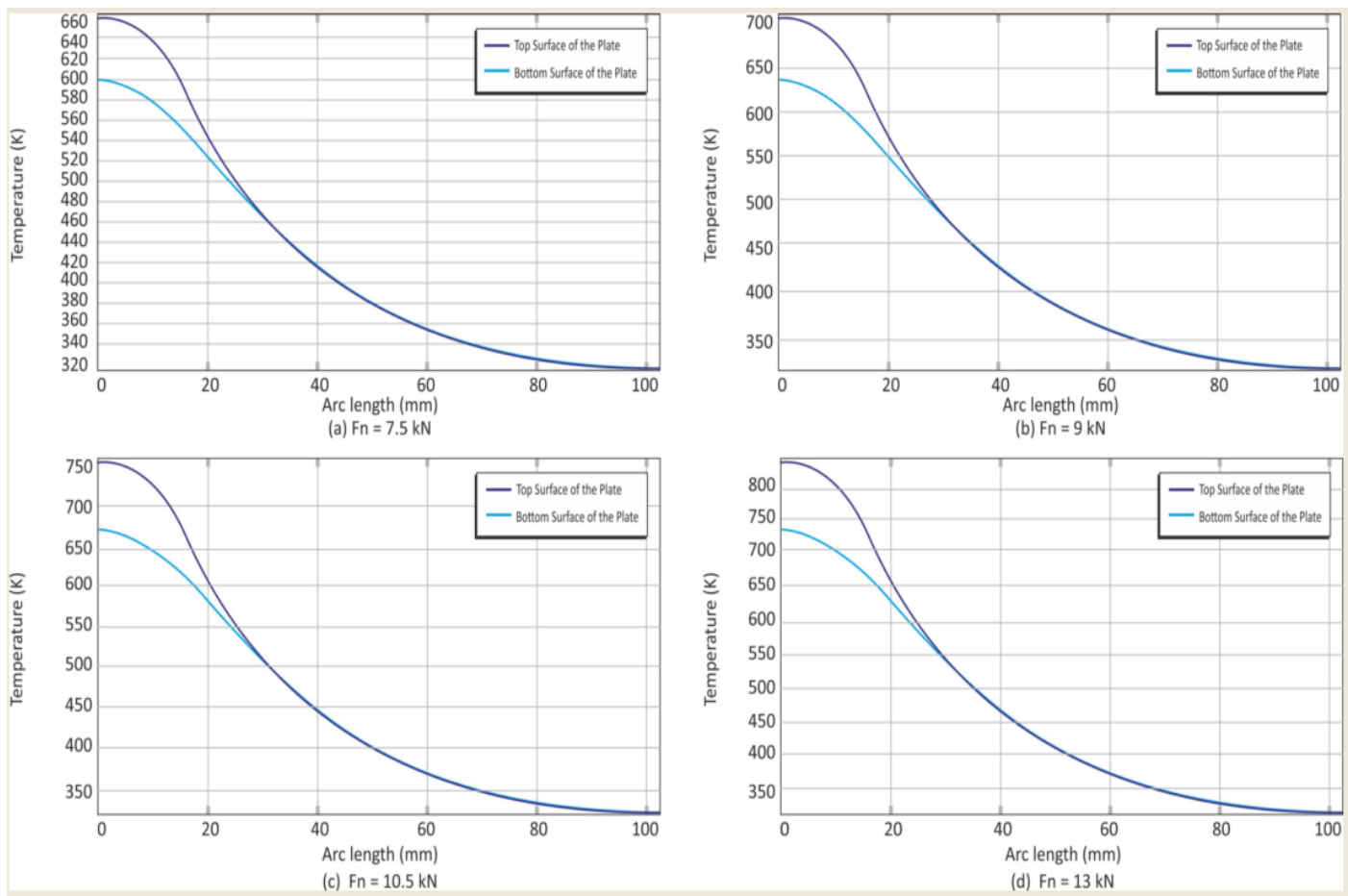

Fig. 7. Variations of temperature with distance along the line perpendicular to the weld line on the top and bottom surfaces as a function of axial force, rotational speed $800 \mathrm{rpm}$ and translational speed $7.5 \mathrm{~mm} / \mathrm{s}$.

\subsection{Effect of Rotational Speed}

As it is evident, the FSW procedure comprises rotating a tool that goes sideways to the weld junction and plastically stirs the aluminum plates to connect. The plastic deformation and material flow near the top surface accelerate tool rotation. Therefore material deformation on the top surface near the contact area is greater than the area on the bottom side. Plastic deformation is critical in creating the weld zone profile during FSW procedures (Jamshidi Aval et al., 2011). This phenomenon is affected by tool rotation. Consequently, the employed model was utilized to simulate various values of rotational tool speed to explore the influence of rotation speed. Fig. 8 shows the variation of maximum temperature as a function of rotation speed. According to these findings, the peak temperature increases linearly with rotating speed. Fig. 9 shows the estimated maximum temperature value of $834 \mathrm{~K}$ with a rotation of $700 \mathrm{rpm}$ under the stated parameters and its distribution and location. In contrast, the findings indicate a similar trend to the simulated results (Chiumenti et al., 2013).

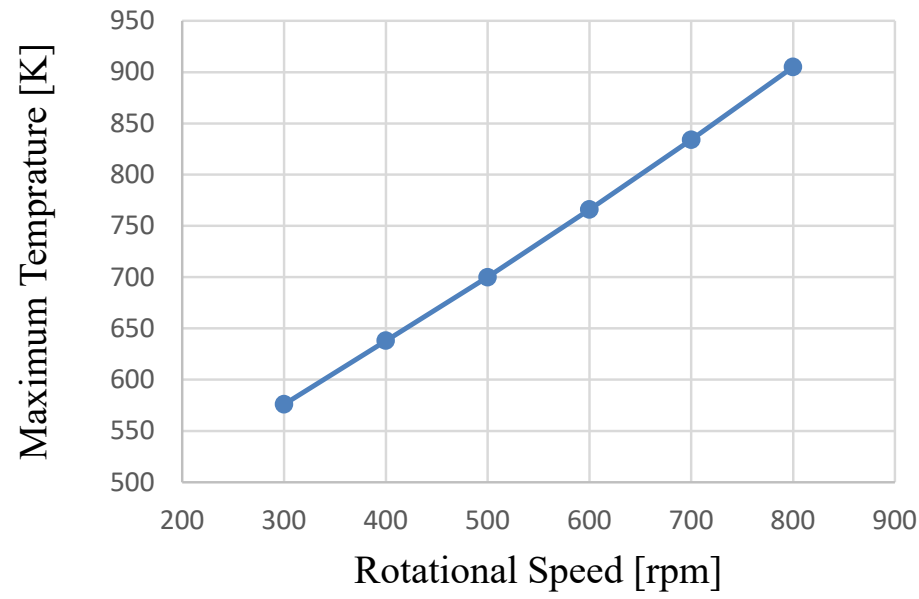

Fig. 8. Variation of Maximum Temperature as a function of rotational speed, axial force $15 \mathrm{kN}$ and translational speed $7.5 \mathrm{~mm} / \mathrm{s}$ 


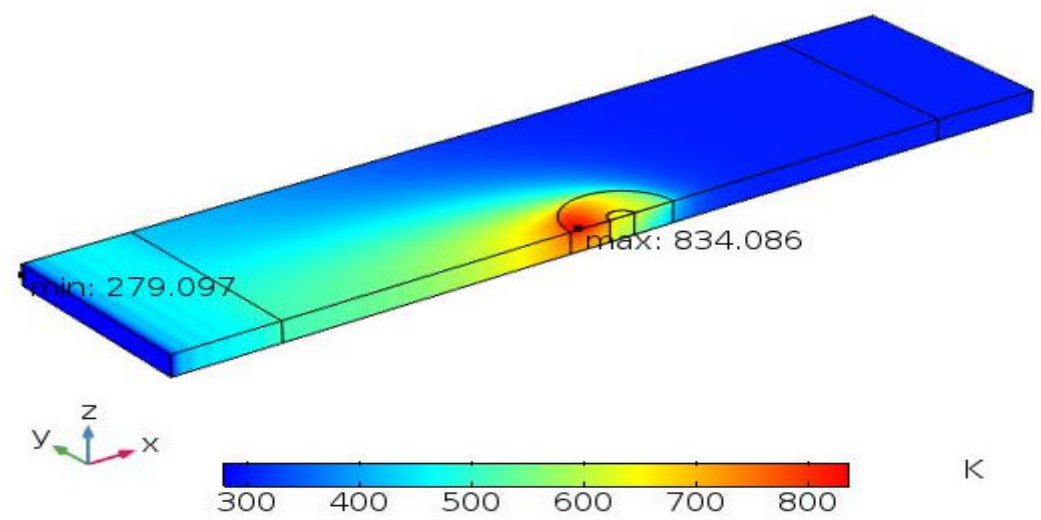

Fig. 9. Magnitude and location of maximum temperature for rotational speed $700 \mathrm{rpm}$. Welding speed of 10 $\mathrm{mm} / \mathrm{s}$ and axial force $15 \mathrm{kN}$

However, the optimum operating temperature for AA 6061-T6 material is between $653 \mathrm{~K}$ and $840 \mathrm{~K}$ to achieve an excellent process zone. Because the friction coefficient and other geometrical variables like the radius of the shoulder pin are constant in this study, the increasing trend in rotational speed should be compensated for by decreasing the applied force.

\subsection{Effect of Translational Speed}

With a steady axial force of $15 \mathrm{kN}$ and a rotational speed of $800 \mathrm{rpm}$, Fig. 10 indicates the temperature difference for various translational welding rates. Fig. 11 suggests that the applied vertical force and tool rotational speed are held stable, the peak temperature falls linearly as the translational speed or welding feeding rate rises. Also, as stated by Meena et al., (2020), the reason behind this decrement is the reduction of the contact time per unit area of tool specimen interface as the welding speed or feeding rate increases. Under the given input parameters, the acceptable peak value of the temperature is calculated as $832 \mathrm{~K}$ for welding of $10 \mathrm{~mm} / \mathrm{s}$, and its distribution together with location is displayed in Fig. 10.

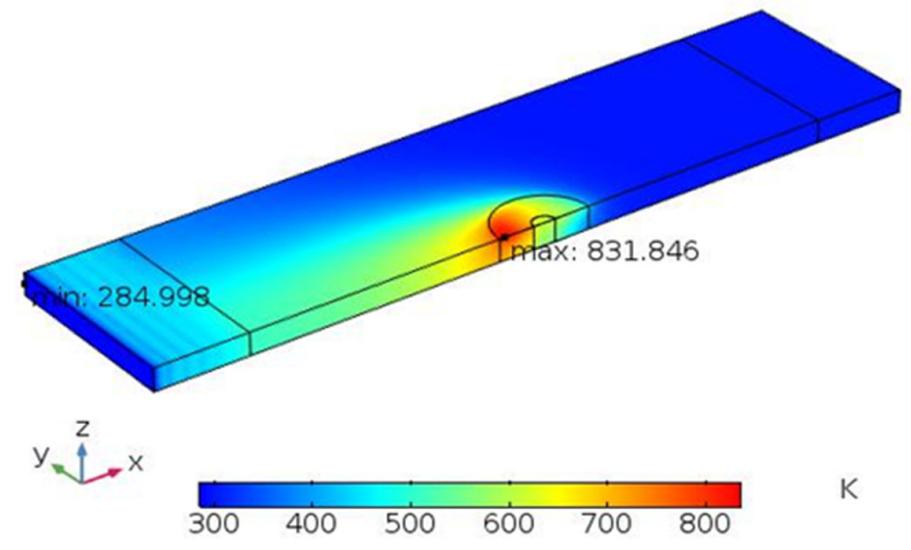

Fig. 10. Magnitude and location of maximum temperature for welding speed of $10 \mathrm{~mm} / \mathrm{s}$, axial force $15 \mathrm{kN}$ and rotational speed $800 \mathrm{rpm}$ 


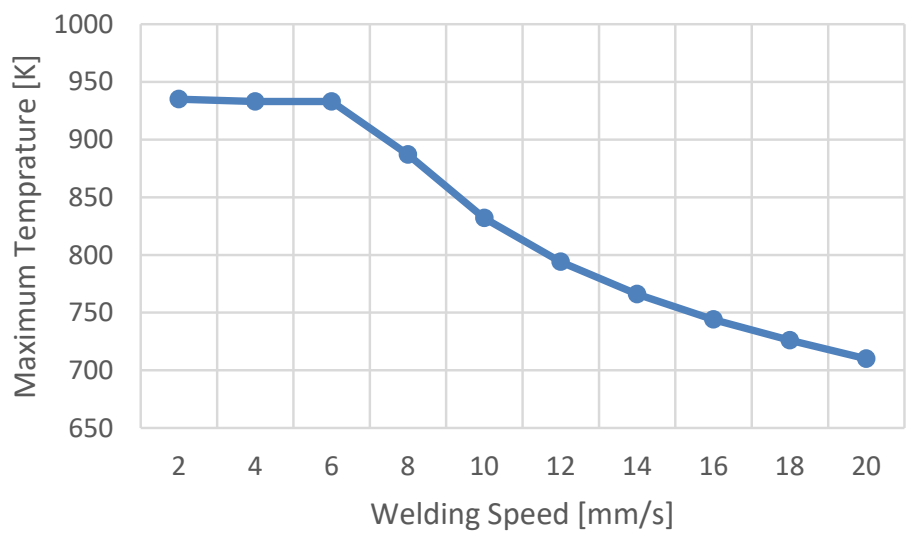

Fig. 11. Variation of Maximum Temperature as a function of translational speed, axial force $15 \mathrm{kN}$ and rotational speed $800 \mathrm{rpm}$

\subsection{Structural Analysis}

The coupled thermomechanical modeling methodology used in this study allows for a realistic simulation of the work piece structural reaction during the FSW operation. Mechanical responses such as thermal stress and strain developed as a result of the process's thermal gradients. The mathematical formulations, as well as the boundary conditions, are addressed for practical estimation. These boundary conditions are shown in Fig. 2. This type of calculation helps determine how much plastic deformation affects the joint's performance in operating conditions. Fig. 12 (a) and 12 (b) show the thermally induced total vertical displacement and effective plastic strain, respectively, as shown from the spinning and traveling pin reference point.

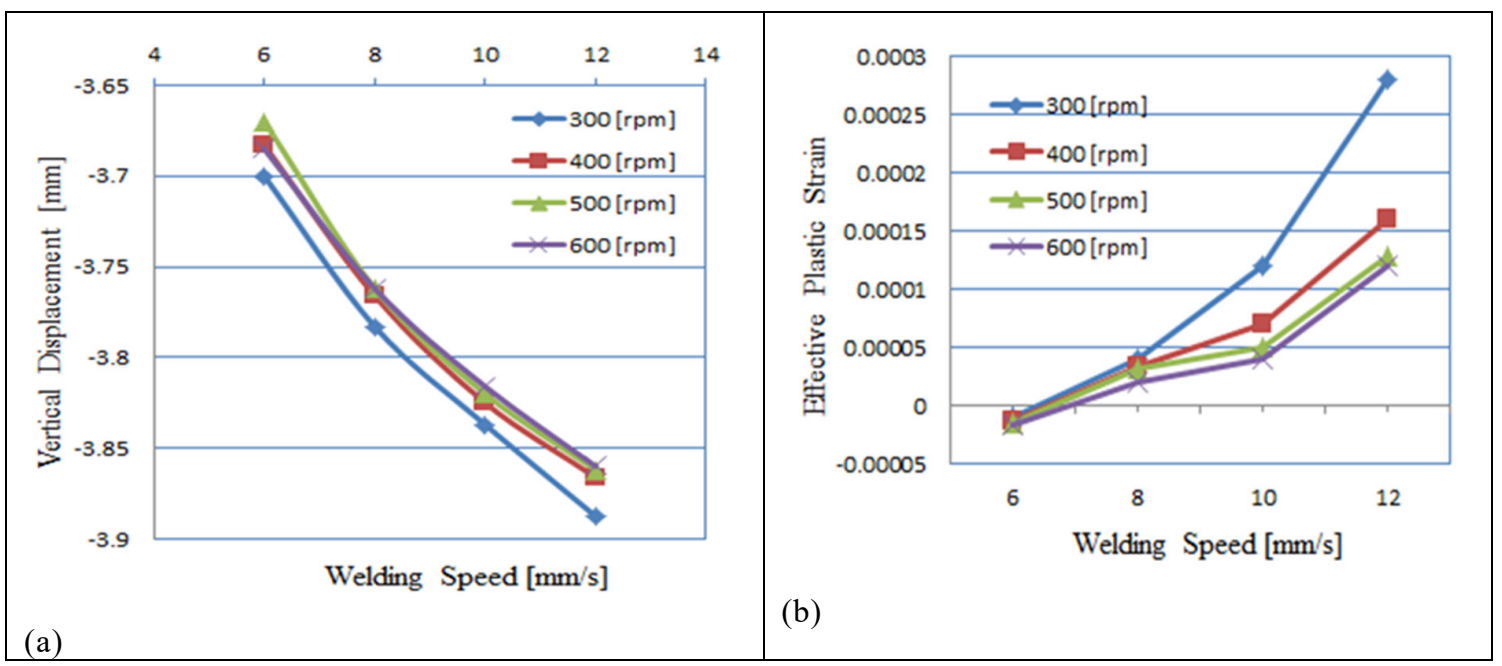

Fig. 12. Variation of (a) vertical displacement (b) plastic strain as a function of welding and rotational speeds at the location where the axis of rotation intersects the work piece surface

It has been observed that increasing welding speed increases the observed thermal stress and the resulting successful plastic strain. The consequence of the velocity term in Eq. (1) may cause this phenomenon. The enhancement is more significant at lower rotational speeds due to the angular velocity term in Eq. (2), which implies that the more heat flux produced at the tool-workpiece interface, the better. The shear yield strength affects the heat flux, as shown in Eq. (3). Since this yield strength is temperature-based, the yield strength decreases more than the rotational speed increases in their contributions in Eq. 3. Consequently, as the tool rotates quicker, the rise in thermal stress and strain is minimized due to a reduction in the material shear yield strength, as shown in Table 2.

As from the data, they were minimizing residual shrinkage (that is, minimizing total displacement or plastic strain) and maximizing welding speed are also critical for improving the efficiency of the FSW operation. However, these 
two parameters are aggressive to one another. As a result, recommendations for more multi-purpose FSW parameters are needed.

\section{Conclusion}

Based on the findings of the present investigation, the following conclusions can be drawn. Base metal Aluminium (AA6061-T6) exhibited the best characteristics for Friction Stir Welding. The maximum temperature increases as the axial force increases within the acceptable value of the induced temperature range of the workpiece material while rotational and welding speeds are constant, and the temperature decreases along the line perpendicular to the weld direction on top and bottom surfaces. The temperature distribution on the top surface is more significant than the bottom one. The maximum temperature increases linearly as the rotation speed of the tool increases within the acceptable induced temperature range of the workpiece material. In contrast, axial force and welding speeds are constant. The maximum temperature decreases as the forward welding speed increases within the workpiece material's acceptable induced temperature range while axial force and rotational speeds are consistent. Welding speed significantly impacts the measured residual thermal stress and associated strains. Higher heat input and slower welding speed are more significant parameters for the softening of the workpiece around the welding region.

\section{References}

Akbari, M., Aliha, M. R. M., Keshavarz, S. M. E., \& Bonyadi, A. (2019). Effect of tool parameters on mechanical properties, temperature, and force generation during FSW. Proceedings of the Institution of Mechanical Engineers, Part L: Journal of Materials: Design and Applications, 233(6), 1033-1043.

Aliha, M. R. M., Ghoreishi, S. M. N., Imani, D. M., Fotoohi, Y., \& Berto, F. (2020). Mechanical and fracture properties of aluminium cylinders manufactured by orbital friction stir welding. Fatigue \& Fracture of Engineering Materials \& Structures, 43(7), 1514-1528.

Aliha, M. R. M., Kalantari, M. H., Ghoreishi, S. M. N., Torabi, A. R., \& Etesam, S. (2019). Mixed mode I/II crack growth investigation for bi-material FSW Aluminum alloy AA7075-T6/pure copper joints. Theoretical and Applied Fracture Mechanics, 103, 102243.

Atharifar, H., Lin, D., \& Kovacevic, R. (2009). Numerical and experimental investigations on the loads carried by the tool during friction stir welding. Journal of Materials Engineering and Performance, 18(4), 339-350.

Backar, A., Elhofy, M., \& Nassef, G. (2020). Finite Elements Modelling of Friction Stir Welding. International Journal of Advanced Science and Technology, 29(0), 29-43.

Bejan, A., \& Kraus, A. D. (2003). Heat Transfer Handbook- Heat Exchangers. In Heat Transfer Handbook (Issue v. 1).

Chao, Y. J., Qi, X., \& Tang, W. (2003). Heat transfer in friction stir welding - Experimental and numerical studies. Journal of Manufacturing Science and Engineering, Transactions of the ASME, 125(1), 138-145.

Chiumenti, M., Cervera, M., Agelet de Saracibar, C., \& Dialami, N. (2013). Numerical modeling of friction stir welding processes. Computer Methods in Applied Mechanics and Engineering, 254, 353-369.

Colegrove, P. (2000). 3 Dimensional Flow and Thermal Modelling of the Friction Stir Welding Process. 2nd International Symposium on Friction Stir Welding, January, 1-11.

El-Sayed, M. M., Shash, A. Y., \& Abd-Rabou, M. (2018). Finite element modeling of aluminum alloy AA5083-O friction stir welding process. In Journal of Materials Processing Technology, 252. Elsevier B.V.

Ganesh, P., \& Kumar, V. S. S. (2011). Finite Element Simulation in Superplastic forming of Friction Stir Welded Aluminium Alloy 6061-T6. International Journal of Integrated Engineering, 3(1), 9-16.

Gök, K., \& Aydin, M. (2013). Investigations of friction stir welding process using finite element method. International Journal of Advanced Manufacturing Technology, 68(1-4), 775-780.

Guo, J. F., Chen, H. C., Sun, C. N., Bi, G., Sun, Z., \& Wei, J. (2014). Friction stir welding of dissimilar materials between AA6061 and AA7075 Al alloys effects of process parameters. Materials and Design, 56, 185-192.

Hamilton, C., Dymek, S., \& Sommers, A. (2008). A thermal model of friction stir welding in aluminum alloys. International Journal of Machine Tools and Manufacture, 48(10), 1120-1130.

Hetnarski, R. B., \& Eslami, M. R. (2009). Thermal Stresses - Advanced Theory and Applications (41st ed.). Springer New York.

Iqbal, M. P., Jain, R., \& Pal, S. K. (2019). Numerical and experimental study on friction stir welding of aluminum alloy pipe. Journal of Materials Processing Technology, 274(May), 116258.

Jain, S., Sharma, N., \& Gupta, R. (2018). Dissimilar alloys (AA6082/AA5083) joining by FSW and parametric optimization using Taguchi, grey relational and weight method. Engineering Solid Mechanics, 6(1), 51-66.

Jamshidi Aval, H., Serajzadeh, S., \& Kokabi, A. H. (2011). Evolution of microstructures and mechanical properties in similar and dissimilar friction stir welding of AA5086 and AA6061. Materials Science and Engineering A, 528(28), 8071-8083.

Kiral, B. G., Tabanoglu, M., \& Serindag, H. T. (2013). Finite element modeling of friction stir welding in aluminum alloys joint. Mathematical and Computational Applications, 18(2), 122-131.

Kumar, K., \& Aggarwal, M. L. (2015). Finite element analysis and optimization of a mono parabolic leaf spring using cae software. Engineering Solid Mechanics, 3(2), 85-92.

Marazani, T., Akinlabi, E., Madyira, D., Majumdar, J., \& Pal, S. (2021). Microstructural, elemental, mechanical and structural attributes of AA1100/17-4 PH stainless steel composites fabricated via friction stir processing. Engineering Solid Mechanics, 9(4), 391-414. 
Meena, S. L., Murtaz, Q., Walia, R. S., \& Niranjan, M. S. (2020). Optimization of Hybrid Friction Stir Welding Process Parameters of Aluminium AA6063. 29(10), 6938-6949.

Meyghani, B., \& Awang, M. (2020). Developing a Finite Element Model for Thermal Analysis of Friction Stir Welding (FSW) Using Hyperworks. Lecture Notes in Mechanical Engineering, 619-628.

Meyghani, B., Awang, M. B., Emamian, S. S., Mohd Nor, M. K. B., \& Pedapati, S. R. (2017). A comparison of different finite element methods in the thermal analysis of friction stir welding (FSW). Metals, 7(10), 1-23.

Meyghani, B., Awang, M., Emamian, S., \& Mohd Nor, M. K. B. (2019). Thermal Modelling of Friction Stir Welding (FSW) Using Calculated Young's Modulus Values. In Lecture Notes in Mechanical Engineering. Springer Singapore.

Mishra, R. S., \& Ma, Z. Y. (2005). Friction stir welding and processing. Materials Science and Engineering R: Reports, 50(12), 1-78.

Mohammadaliha, M. R., Fotouhi, Y., \& Berto, F. (2018). Experimental notched fracture resistance study for the interface of Al-Cu bimetal joints welded by friction stir welding. Proceedings of the Institution of Mechanical Engineers, Part B: Journal of Engineering Manufacture, 232(12), 2192-2200.

Moreira, P. M. G. P., Santos, T., Tavares, S. M. O., Richter-Trummer, V., Vilaça, P., \& de Castro, P. M. S. T. (2009). Mechanical and metallurgical characterization of friction stir welding joints of AA6061-T6 with AA6082-T6. Materials and Design, 30(1), 180-187.

Narasimharaju, S., \& Sankunny, S. (2019). Microstructure and fracture behavior of friction stir lap welding of dissimilar AA 6060-T5/Pure copper. Engineering Solid Mechanics, 7(3), 217-228.

Nguyen, N. T., Kim, D. Y., \& Kim, H. Y. (2011). Assessment of the failure load for an AA6061-T6 friction stir spot welding joint. Proceedings of the Institution of Mechanical Engineers, Part B: Journal of Engineering Manufacture, 225(10), $1746-1756$.

Obiko, J., \& Mwema, F. (2020). Deformation behaviour of high-strength aluminium alloy during forging process using finite element method. Engineering Solid Mechanics, 9(1), 31-40.

Prasanna, P., Rao, B. S., \& Rao, G. K. M. (2010). Finite element modeling for maximum temperature in friction stir welding and its validation. International Journal of Advanced Manufacturing Technology, 51(9-12), 925-933.

Prasanna, P., Subba Rao, B., \& Krishna Mohana Rao, G. (2010). Experimental and numerical evaluation of friction stir welds of AA6061-T6 Aluminium alloy. Journal of Engineering and Applied Sciences, 5(6), 1-18.

Riahi, M., \& Nazari, H. (2011). Analysis of transient temperature and residual thermal stresses in friction stir welding of aluminum alloy 6061-T6 via numerical simulation. International Journal of Advanced Manufacturing Technology, 55(14), 143-152.

Schmidt, H., Hattel, J., \& Wert, J. (2004). An analytical model for the heat generation in friction stir welding. Modelling and Simulation in Materials Science and Engineering, 12(1), 143-157.

Shubhavardhan, R., \& Surendran, S. (2018). Microstructure and fracture behavior of friction stir lap welding of dissimilar metals. Engineering Solid Mechanics, 6(1), 1-10.

Taheri-Behrooz, F., Aliha, M. R., Maroofi, M., \& Hadizadeh, V. (2018). Residual stresses measurement in the butt joint welded metals using FSW and TIG methods. Steel and Composite Structures, 28(6), 759-766.

Torabi, A. R., Kalantari, M. H., \& Aliha, M. R. M. (2018). Fracture analysis of dissimilar Al-Al friction stir welded joints under tensile/shear loading. Fatigue \& Fracture of Engineering Materials \& Structures, 41(9), 2040-2053.

Torabi, A. R., Kalantari, M. H., Aliha, M. R. M., \& Ghoreishi, S. M. N. (2019). Pure mode II fracture analysis of dissimilar $\mathrm{Al}-\mathrm{Al}$ and $\mathrm{Al}-\mathrm{Cu}$ friction stir welded joints using the generalized MTS criterion. Theoretical and Applied Fracture Mechanics, 104, 102369.

Vignesh, R. V., Padmanaban, R., Arivarasu, M., Thirumalini, S., Gokulachandran, J., \& Ram, M. S. S. S. (2016). Numerical modelling of thermal phenomenon in friction stir welding of aluminum plates. IOP Conference Series: Materials Science and Engineering, 149(1).

Zhang, Z., Wu, Q., \& Zhang, H. W. (2016). Prediction of fatigue life of welding tool in friction stir welding of AA6061-T6. International Journal of Advanced Manufacturing Technology, 86(9-12), 3407-3415.

Zhu, X. K., \& Chao, Y. J. (2004). Numerical simulation of transient temperature and residual stresses in friction stir welding of 304L stainless steel. Journal of Materials Processing Technology, 146(2), 263-272.

Zhu, Z., Wang, M., Zhang, H., Zhang, X., Yu, T., \& Wu, Z. (2017). A finite element model to simulate defect formation during friction stir welding. Metals, 7(7).

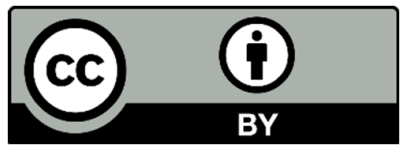

(C) 2022 by the authors; licensee Growing Science, Canada. This is an open access article distributed under the terms and conditions of the Creative Commons Attribution (CC-BY) license (http://creativecommons.org/licenses/by/4.0/). 